\title{
VALUE OF NON-INVASIVE FETAL MONITORING TECHNIQUES IN DETECTION OF FETAL METABOLIC ACIDEMIA AT BIRTH
}

\author{
Dokus $\mathrm{K}^{1}$, Matasova $\mathrm{K}^{2}$, Visnovsky $\mathrm{J}^{1}$, Dokusova $\mathrm{S}^{3}$, Danko $\mathrm{J}^{1}$ \\ ${ }^{1}$ Dept. of Obstetrics and Gynaecology, Jessenius Faculty of Medicine, Comenius University, Martin, Slovakia \\ ${ }^{2}$ Dept. of Neonatology, Jessenius Faculty of Medicine, Comenius University, Martin, Slovakia \\ ${ }^{3}$ National Endocrinology and Diabetology Institute, Lubochna, Slovakia
}

\begin{abstract}
A bstract
Objective. Purpose of the study was to evaluate the diagnostic accuracy of fetal pulse oximetry (FPO) and STanalysis of the fetal ECG (STAN) in prediction of fetal acidemia at birth. Methods. A prospective clinical study was conducted at the Department of Obstetrics and Gynaecology, Jessenius Faculty of Medicine, Martin, Slovakia. In total, 63 out of 70 women with non-reassuring CTG patterns in labour were enrolled. Fetal surveillance during the labour continued with simultaneous CTG plus FPO and STAN monitoring. A receiver operating curve (ROC) analysis was performed to ascertain diagnostic accuracy of individual methods. Results. The study confirmed FPO has a significant ability to detect fetal acidemia at birth (UA-pH $\leq 7.2$ ). The optimum diagnostic cut-off value of SpO2 was $33 \%$, with FPO's diagnostic sensitivity $60 \%$, and specificity $85.2 \%$. The diagnostic accuracies of STAN + CTG and CTG alone were inferior to that of FPO. Conclusions. FPO has an ability to predict fetal birth acidemia (UA-pH $\leq 7.2$ ), and its diagnostic accuracy is superior to STAN + CTG, or CTG alone monitoring. Condensation.FPO has ability to predict fetal birth acidemia (UA - pH $\leq 7.2)$, and its diagnostic accuracy is superior to STAN + CTG, or CTG alone monitoring.
\end{abstract}

Key words: fetal pulse oximetry; ST-analysis of the fetal ECG; cardiotocography; diagnostic accuracy; fetal monitoring

\section{INTRODUCTION}

At present, cardiotocography (CTG) is considered a standard of fetal surveillance in labour, despite it has caused escalation in Caesarean rates for non-reassuring CTG patterns [1]. Adding fetal scalp blood sampling (FBS) to CTG has been shown to combat this adverse effect, nonetheless, its invasive nature, and a need for repeated testing have limited its current use to minimum [2].

During the past decade 2 novel non-invasive biophysical fetal monitoring methods, the fetal pulse oximetry (FPO) and the ST-analysis of the fetal ECG (STAN), have become clinically available with the aim at increasing diagnostic accuracy of CTG in prediction of fetal acidosis at birth. FPO enables continuous measurement of the oxygen saturation (SpO2) of the fetal haemoglobin. Studies have shown a shift in SpO2 correlates well with the $\mathrm{pH}$ changes in the fetal blood. Several RCT trials then reported on a reduction in Caesarean rate for non-reassuring CTG patterns if FPO is used as adjunct to CTG. However, these studies proved also a lack for an effect on the total number of Caesarean deliveries [3 -5]. Surprisingly, during the U.S. multi-centre study fetal SpO2 readings were also found in fetuses with normal CTG patterns [6].

The latter of the methods, STAN, checks for hypoxia-related changes in the fetal ECG. These appear as increases (baseline, episodic) in the T/QRS ratio and/or bi-phasic ST waveforms (BP). If changes become significant, these would be designated as 'ST event' on CTG strip. STAN interpretation depends on a concurrent CTG interpretation. A Swedish RCT trial showed that STAN could improve not only fetal assessment, but perinatal outcome, as well $[7,8]$. These findings, however, were brought in question in a later study by Ojala et al., who have proved the only benefit of STAN in the decreased need for FBS testing in labour.

Address for correspondence:

Karol Dokus, MD, PhD, Kollarova 2, 03608 Martin, Slovakia

Tel/fax: 00421-43-4134185; e-mail: dokus@jfmed.uniba.sk 
Moreover, the higher frequency of fetal metabolic acidosis was observed during CTG + STAN compared to CTG alone monitoring [9, 10]. Recently, a few cases of missed severe fetal metabolic acidosis with no ST changes in labour have been described [11].

The purpose of this study was to assess the diagnostic accuracy of FPO and STAN as adjuncts to a standard CTG monitoring in prediction of fetal metabolic acidemia at birth. Both ancillary techniques were used simultaneously during labour in order to ease comparison.

\section{METHODS}

A prospective clinical trial was conducted at the Department of Obstetrics and Gynaecology, Jessenius Faculty of Medicine, Martin, Slovakia. Women were included if during their labour non-reassuring CTG patterns developed necessitating further fetal assessment. This was accomplished by simultaneous and continuous CTG plus FPO and STAN monitoring. The information on the SpO2 and STAN data has been left clinically available and all labours could have been managed accordingly. Nevertheless, final decision on management was left upon discretion of a trained attending obstetrician. The scalp FBS was not a part of the labour management protocol. All women were informed about the aims of the study and gave their consent. The local faculty's Ethics committee has approved the study protocol.

Study inclusion criteria were as follows: a singleton pregnancy $>36$ weeks, vertex presentation, the cervix dilated to at least $3 \mathrm{~cm}$ to allow for fetal sensors placement, and ruptured membranes. Women were excluded if there were a serious vaginal bleeding, maternal infections (HSV 2, HBV), and if the lastly registered readings of FPO and STAN preceded delivery by $>20$ minutes. In this situation readings were not expected to accurately correspond to the birth umbilical $\mathrm{pH}$ values. Therefore, fetal sensors were left in place until the fetus was delivered or the preparation for a Caesarean section started.

Fetal SpO2 measurement was accomplished using a Nellcor N-400 oximeter with FS-14C fetal sensor (Nellcor Puritan Bennett, Pleasanton, USA) that was interfaced to a CTG monitor series 50A (Philips Medical Systems). SpO2 data were simultaneously recorded onto a CTG strip within the uterine contractions scale. As a $\mathrm{SpO} 2$ value suggestive of fetal acidemia we assumed values $<30 \%$ lasting $\geq 10$ minutes [12].

STAN monitoring was accomplished with STAN S21 monitor (Neoventa Medical, Gotheborg, Sweden) that simultaneously records CTG and STAN data on a CTG strip. STAN clinical assessment was done using the proposed clinical guidelines [13].

During non-reassuring CTG patterns general measures to improve fetal oxygenation and placental perfusion (maternal mask oxygen and lateral positioning, fetal scalp stimulation, intravenous fluids and oxytocin cessation) could have been exploited to elicit fetal reactivity and to exclude fetal acidosis [14]. Preterminal CTG patterns (complete loss of variability and reactivity with or without decelerations and bradycardia) would have led to expedited delivery. Common medication including oxytocin, spasmolytic agents, and epidural analgesia were allowed during all labours.

Neonatal condition was thoroughly evaluated by an attending neonatologist. In each case, a paired umbilical blood sample was taken for acid-base balance analysis. All samples have been analysed on a Rapidlab 1265 blood gas analyser (Bayer Diagnostics, Sudbury, UK) installed in the delivery room.

\section{Registered data handling and statistical analyses}

The diagnostic accuracy of the methods was evaluated using a receiver operating curve (ROC) analysis. The study-specific fetal acidemia at birth was defined by umbilical arterial $\mathrm{UA}-\mathrm{pH} \leq 7.2$. Fetal SpO2 data, STAN recordings and CTG patterns were statistically analysed and correlated to the umbilical artery $\mathrm{pH}$ values. The SpO2 mean value was cal- 
culated and used as a reference value representing fetal oxygenation status before delivery. This was calculated out of 10 readings separated by 60s intervals within the lastly registered SpO2 readings. This method was chosen for 2 reasons: a) the Nellcor oximeter always displays SpO2 mean for 45 seconds of its measurement, and b) the 10-minute duration of low SpO2 readings $(<30 \%)$ was recognized by previous studies as suggestive of fetal hypoxia [12]. The last 30 minutes of CTG monitoring before the delivery was used as a reference for CTG patterns that were evaluated in accordance with the FIGO classification (1987). This study specific scoring system for CTG patterns was devised to ease statistical analysis of the registered data (Tab. 1). An analogous scoring system was devised to analyse STAN + CTG recordings, too (Tab. 2). The level of statistical significance was assumed $\mathrm{P}=0.05$. Statistical analysis was done using MedCalc 9.2.0.0 statistical software (MedCalc, Mariakerke, Belgium).

Table 1. The study's scoring system for CTG patterns.

\begin{tabular}{|c|c|c|c|}
\hline \multicolumn{3}{|c|}{ CTG patterns } \\
\hline Normal & Suspicious & Pathological & Preterminal \\
0 & 1 & 2 & 3 \\
\hline
\end{tabular}

Table 2. The study's scoring system for STAN + CTG recordings. Scores 2 and 3 necessitate expedited delivery while continuous monitoring is assumed for scores 0 and 1.

\begin{tabular}{|l|c|c|c|}
\hline $\begin{array}{l}\text { STAN } \\
\text { (ST changes) }\end{array}$ & $\begin{array}{c}\text { Suspicious } \\
0\end{array}$ & $\begin{array}{c}\text { PTG patterns } \\
0\end{array}$ & Preterminal \\
\hline $\begin{array}{l}\text { Normal } \\
\text { (no) }\end{array}$ & 1 & 1 & 3 \\
\hline $\begin{array}{l}\text { Suspicious } \\
\text { (non-significant) }\end{array}$ & 2 & 2 & \\
\hline $\begin{array}{l}\text { Pathological } \\
\text { (significant) }\end{array}$ & & & \\
\hline
\end{tabular}

\section{RESULTS}

The concomitant fetal sensor placement (FPO and STAN) was successfully accomplished in 70 women enrolled to the study. However, 7 of these were excluded from further analysis, because of the lastly registered SpO2 and/or STAN data preceded delivery by more than 20 minutes. Out of 63 labours analysed, 19 (30\%) women delivered by a Caesarean section, $9(14 \%)$ of these were indicated for non-reassuring fetal status in labour, and $10(16 \%)$ for labour dystocia. There were no instrumental vaginal deliveries.

Thirty-one women in total (49\%) had epidural analgesia, 17 (27\%) of these delivered vaginally, and $14(22 \%)$ had a Caesarean section. The mean age was $28.5+-5.5$ (SD) years, and parity $1.8+-1.5$ (SD). The mean birth weight of the neonates was $3422+-352$ (SD) grams. The mean Apgar score at 1, 5 and 10 minutes of life were 9, 9 and 10, respectively. There were 5 cases of significant birth acidemia study-defined with UA - $\mathrm{pH} \leq 7.2$. Out of these, 2 neonates had 1' Apgar score 7, the rest $\geq 8$ (Tab. 3). There were no perinatal deaths, or cases of neonatal sepsis. 
Table 3 Characteristics of cases with birth metabolic acidemia as defined by UA-pH $\leq 7.2$. All CTG patterns were pathological except No. 3 that was suspicious.

\begin{tabular}{|c|c|c|c|c|c|c|c|c|c|c|c|c|c|c|}
\hline \multirow{2}{*}{$\begin{array}{c}\text { Case } \\
\text { No. }\end{array}$} & \multirow{2}{*}{ Parity } & \multirow{2}{*}{$\begin{array}{l}\text { Delivery } \\
\text { mode }\end{array}$} & \multirow{2}{*}{ Indication } & \multicolumn{11}{|c|}{ STAN $\mathrm{SpO}_{2}$ UA UV Apgar BW } \\
\hline & & & & $\begin{array}{l}\mathrm{T} / \mathrm{QRS} \\
\text { baseline }\end{array}$ & $\begin{array}{l}\mathrm{T} / \mathrm{QRS} \\
\text { rise }\end{array}$ & $\mathrm{BP}$ & $(\%)$ & $\mathrm{pH}$ & $\mathrm{BD}$ & $\mathrm{pH}$ & $\mathrm{BD}$ & 1 & 5 & (g) \\
\hline 1 & 0 & Caesarean & Dystocia & 0.11 & - & - & 52 & 7.2 & 6.4 & 7.26 & 5.5 & 8 & 9 & 3600 \\
\hline 2 & 0 & Caesarean & $\begin{array}{l}\text { Fetal distress } \\
\text { (CTG) }\end{array}$ & 0.14 & - & - & 26 & 7.19 & 8.3 & 7.27 & 7.5 & 8 & 9 & 3680 \\
\hline 3 & 3 & Vaginal & & 0.15 & Episodic & - & 43 & 7.15 & 6.7 & 7.21 & 4.9 & 8 & 9 & 2640 \\
\hline 4 & 1 & Vaginal & & 0.08 & - & - & 33 & 7.12 & 8.4 & 7.17 & 7.7 & 7 & 8 & 3320 \\
\hline 5 & 0 & Vaginal & & 0.17 & - & - & 46 & 7.1 & 8.2 & 7.13 & 7.3 & 7 & 8 & 3540 \\
\hline
\end{tabular}

Legend: UA, UV = umbilical artery and vein, $\mathrm{BW}=$ birth weight, $\mathrm{BP}=$ biphasic $\mathrm{ST}$ waveform, $\mathrm{BD}=\mathrm{base}$ deficit

An ROC analysis showed that out of the methods, FPO has the best and significant accuracy in prediction of fetal acidemia at birth, here defined by UA $\mathrm{pH} \leq 7.2$ (Tab. 4 and Fig. 1). The related optimal diagnostic SpO2 cut-off value was 33\%, with sensitivity $60.0 \%$, and specificity $85.2 \%$. A combined STAN + CTG monitoring had inferior diagnostic accuracy. In this case, the optimal diagnostic cut-off was significant ST changes with non-reassuring CTG patterns (score 2 in Tab. 2). However, diagnostic accuracy of CTG alone monitoring was superior to that of CTG + STAN monitoring, though insignificantly (Tab. 4). The optimal CTG alone cut-off criterion was represented by a pathological CTG pattern (score 2 in Tab. 1).
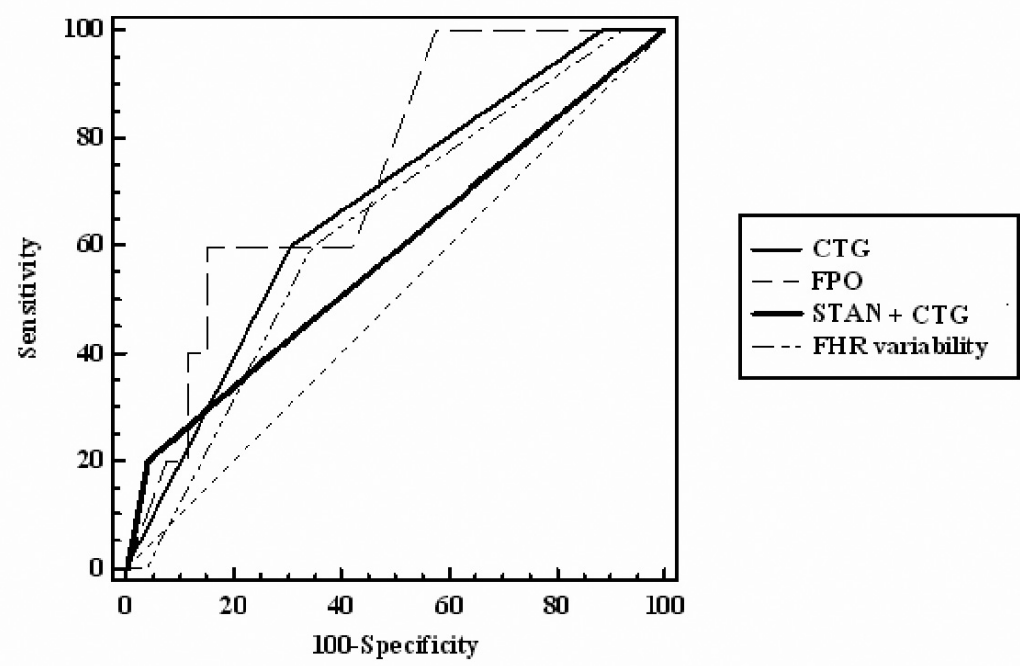

Fig. 1 ROC curves plotting sensitivity and specificity of the methods for detection of fetal metabolic acidosis at birth (UA-pH $\leq 7.2$ ). 
Table 4. Areas under ROC curves (AUC) for diagnostic methods used in the study.

\begin{tabular}{|c|c|c|c|}
\hline Diagnostic method & AUC & $95 \%$ CI & P \\
\hline FPO & 0.744 & $0.560-0.881$ & 0.021 \\
\hline STAN + CTG & 0.583 & $0.402-0.749$ & NS \\
\hline CTG & 0.683 & $0.501-0.831$ & NS \\
\hline FHR variability & 0.643 & $0.458-0.801$ & NS \\
\hline
\end{tabular}

\section{DISCUSSION}

In general, fetal surveillance in labour aims at early detection of fetal jeopardy that may lead to otherwise preventable neonatal morbidity and mortality. As non-reassuring CTG patterns are not specific for fetal hypoxia/acidosis, CTG has substantially raised the rate of Caesarean deliveries for non-reassuring fetal status. FPO and STAN techniques have been devised to improve our knowledge of the fetal condition in labour, thus decreasing avoidable obstetric surgery $[3,7]$.

Our aim in this study was to test diagnostic accuracy of FPO, STAN and CTG in detection of a birth acidemia. We found that only FPO is significantly capable to detect fetal acidemia at birth if it is defined by $\mathrm{UA}-\mathrm{pH} \leq 7.2$. The related optimal $\mathrm{SpO}_{2}$ cut-off value was $33 \%$ that correlates well with the results of the previous experimental and clinical studies [3, 4, $15,16]$. STAN + CTG monitoring performed inferiorly to FPO, as only 1 acidemia case could be thus detected. Though, combined STAN + CTG monitoring increased CTG specificity for fetal acidemia in our study from $72.4 \%$ to $96.5 \%$, this has also led to a substantial decrease in diagnostic sensitivity from $60 \%$ to $20 \%$ (Fig. 1). The final discriminatory performance of STAN + CTG was below that of CTG alone (Tab. 4). The optimum cut-off criterion for STAN + CTG monitoring identified by our analysis corresponds well to that recommended by the present STAN clinical guidelines [17]. On the basis of our results and the published data [18], the diagnostic accuracy of STAN + CTG might be viewed as suboptimal, which might be reflected in its yet unclear clinical value according to the recent studies on STAN. One of the reasons is seen in difficulty to interpret CTG patterns, that is, unfortunately, an integral part of STAN assessment. Moreover, typical ST changes were shown to be absent due to a complete loss of fetal defence mechanisms occurring in pregnancies complicated by a chronic fetal hypoxia [17].

Another finding of our study is a similarity between diagnostic accuracy of CTG alone and fetal heart rate (FHR) variability (AUC 0.683 vs. 0.643 ) if these were used as a standalone diagnostic criterion (Fig. 1 and Tab. 4). In our opinion, this gives further stress to the role of FHR variability within the CTG phenomena, and its relation to the fetal metabolic status. Indeed, it has been known for long that the normal FHR variability is highly predictive for fetal wellbeing, and makes the diagnosis of fetal acidosis improbable.

Though, all cases of birth acidemia in our study had favourable further prognosis, the identification of only 1 out of 5 cases by CTG + STAN monitoring should be regarded worrisome. We believe that the diagnostic method should warn a clinician as early as during initial phases of the developing acidosis that carry excellent prognosis for the fetus and neonate. At the same time, fetal surveillance should not go beyond limits that are risky for irreversible fetal damage or demise. This was one of the reasons to define our study limit for the fetal birth acidemia relatively high at $\mathrm{UA}-\mathrm{pH} \leq 7.2$.

It is obvious that the absence of a sensitive, and yet highly specific method of fetal intrapartum surveillance would impede general strengths to decrease high Caesarean rates. This 
may be even more escalated due to fears of obstetrical liability in a case of missed perinatal asphyxia.

In conclusion, FPO has an ability to predict fetal birth acidemia (UA-pH $\leq 7.2$ ), and its diagnostic accuracy is superior to that of STAN + CTG, or CTG alone monitoring.

\section{REFERENCES}

1. Thacker SB, Stroup D, Chang M. Continuous electronic heart rate monitoring for fetal assessment during labor. Cochrane Database Syst Rev 2001:CD000063.

2. Henderson Z, Ecker JL. Fetal scalp blood sampling - Limited role in contemporary obstetric practice: Part II. Lab Med 2003;34: 594-600.

3. Garite TJ, Dildy GA, McNamara $\mathrm{H}$ et al. A multicenter controlled trial of fetal pulse oximetry in the management of nonreassuring fetal heart rate patterns. Am J Obstet Gynecol 2000;183: 1049-58.

4. East CE, Colditz PB, Begg LM, Brennecke SP. Update on intrapartum fetal pulse oximetry. Aust N Z J Obstet Gynaecol 2002;42: 119-24.

5. Porreco RP, Boehm FH, Dildy GA et al. Dystocia in nulliparous patients monitored with fetal pulse oximetry. Am J Obstet Gynecol 2004; 190: 113-7.

6. Bloom ST, Spong CY, Thom E et al. Fetal pulse oximetry and Caesarean delivery. N Engl J Med 2006; 355: 2195-2202.

7. Amer-Wahlin I, Hellsten C, Noren H, Hagberg H, Herbst A et al. Intrapartum fetal monitoring: Cardiotocography versus cardiotocography plus ST analysis of the fetal ECG. A Swedish randomized controlled trial. Lancet 2001; 358: $534-8$.

8. Rosen K, Amer-Wahlin I, Luzietti R, Noren H. Fetal ECG waveform analysis. Best Pract Res Clin Obstet Gynaecol 2004, 18: 485-514.

9. Ojala K, Vaarasmaki M, Makikallio K, Valkama M, Tekay A. A comparison of intrapartum automated fetal electrocardiography and conventional cardiotocography — a randomised controlled study BJOG 2006;113: 419-23.

10. Westerhuis M, Porath M, Molb BW, Kwee A. Correspondence: A comparison of intrapartum automated fetal electrocardiography and conventional cardiotocography - a randomised controlled study. BJOG 2006; DOI: $10.1111 /$ j.1471-0528.2006.01029.x

11. Westerhuis M, Kwee A, van Ginkel A, Drogtrop A, Gyselaers W, Visser G. Limitations of ST analysis in clinical practice: three cases of intrapartum metabolic acidosis. BJOG 2007;114: 1194-1201.

12. Seelbach-Gobel B, Heupel M, Kuhnert M, Butterwegge M. The prediction of fetal acidosis by means of intrapartum fetal pulse oxymetry. Am J Obstet Gynecol 1999;180: 73-81.

13. Sundstrom AK, Rosen D, Rosen KG. Fetal Surveillance. Neoventa Medical AB 2006, Textbook. CLD30020144R1A: 40.

14. Skupski DW, Rosenburg CR, Eglinton GS. Intrapartum fetal stimulation tests: a metaanalysis. Obstet Gynecol. 2002;99: 129-134.

15. Schmidt S, Koslowski S, Sierra F, Meyer-Wittkopf M, Heller G. Clinical usefulness of pulse oximetry in the fetus with no-reassuring heart rate pattern? J Perinat Med 2000;28: 298-305.

16. Dokus K, Zubor P, Visnovsky J, Biringer K, Danko J. [Diagnostic accuracy of fetal pulse oximetry in detection of fetal intrapartum hypoxia]. Article in Slovak. Gynekolog 2010;19: 96-101.

17. Amer-Wahlin I, Arulkumaran S, Hagberg H, Marsal K, Visser G. Fetal electrocardiogram: ST waveform analysis in intrapartum surveillance. BJOG 2007;114: 1191-1193.

18. Westerhuis M, Kwee A, van Ginkel A, Drogtrop A, Gyselaers W, Visser G. Limitations of ST analysis in clinical practice: three cases of intrapartum metabolic acidosis. BJOG 2007;114: 1194-1201.

19. East CE, Colditz PB. Intrapartum oximetry of the fetus. Anesth Analg. 2007 Dec;105(6 Suppl): S59-65.

\section{Acknowledgements}

This work was supported by the project „Increasing opportunities for career growth in research and deve lopment in the field of medical sciences“, ITMS 26110230067, co-funded by the EU and the European Social Fund, and the financial grant of the Slovak Research and Development Agency under No. APVT-20-033104.

Received: Sept. 19, 2013

Accepted: October, 4, 2013 